ORIGINAL ARTICLE

\title{
Burnout and work environments of public health nurses involved in mental health care
}

\author{
H Imai, H Nakao, M Tsuchiya, Y Kuroda, T Katoh
}

Occup Environ Med 2004;61:764-768. doi: 10.1136/oem.2003.009134

See end of article for authors' affiliations .....................

Correspondence to: Dr H Imai, Department of Public Health, School of Medicine, Miyazaki Medical College, 5200 Kihara, Kiyotake, Miyazaki Prefecture 8891692, Japan; hiroimai@ post.miyazaki-med.ac.jp

Accepted 24 March 2004

\begin{abstract}
Aims: (1) To examine whether prevalence of burnout is higher among community psychiatric nurses working under recently introduced job specific work systems than among public health nurses (PHNs) engaged in other public health services. (2) To identify work environment factors potentially contributing to burnout.

Methods: Two groups were examined. The psychiatric group comprised $525 \mathrm{PHNs}$ primarily engaged in public mental health services at public health centres (PHCs) that had adopted the job specific work system. The control group comprised $525 \mathrm{PHNs}$ primarily engaged in other health services. Pines' Burnout Scale was used to measure burnout. Respondents were classified by burnout score into three groups: $A$ (mentally stable, no burnout); B (positive signs, risk of burnout); and C (burnout present, action required). Groups B and $C$ were considered representative of "burnout". A questionnaire was also prepared to investigate systems for supporting PHNs working at PHCs and to define emergency mental health service factors contributing to burnout.

Results: Final respondents comprised 785 PHNs. Prevalence of burnout was significantly higher in the psychiatric group (59.2\%) than in the control group (51.5\%). Responses indicating lack of job control and increased annual frequency of emergency overtime services were significantly correlated with prevalence of burnout in the psychiatric group, but not in the control group.

Conclusions: Prevalence of burnout is significantly higher for community psychiatric nurses than for PHNs engaged in other services. Overwork in emergency services and lack of job control appear to represent work environment factors contributing to burnout.
\end{abstract}

$\mathrm{S}$ tress related diseases such as burnout have recently begun to attract attention among medical professionals. ${ }^{1-4}$ Burnout is a syndrome characterised by extreme physical and mental fatigue and emotional exhaustion. $^{5}$ A wide range of professions experience burnout, including physicians, nurses, and educators. The common factor is that all share an intense involvement with people or provide assistance to people. ${ }^{67}$ Burnout represents a problem in the working environment, rather than an internal human problem. Factors identified as contributing to burnout include malignant stressors associated with job and working environment. ${ }^{8}$

In developed countries like the UK and Canada, newly implemented work climates or systems following health reforms and restructuring place considerable stress on district nurses and home care workers. ${ }^{9}{ }^{10}$ For instance, one study reported that many district nurses felt that ongoing changes to the National Health Service represented the largest stressor in the UK. ${ }^{10}$ The environments in which medical professionals work are undergoing profound changes, due to increasing demands in medical care, mounting pressure to keep medical costs down, and reforms to medical care systems. ${ }^{11-14}$ Changes in medical care systems and working environments can act as stressors on medical professionals, resulting in physical and mental burdens. ${ }^{15}{ }^{16}$ In Japan, the work system for public health nurses (PHNs) in public health centres (PHCs) across the country was fundamentally modified in April 1997, when the Community Health Act came into effect. ${ }^{17-19}$ This Act replaced the previous regionspecific work system with a job-specific work system. The resulting changes to the work environment of PHNs working in PHCs seem to be contributing to various types of mental stress.

Under the region specific work system, PHNs were involved with all public health activities in a given region.
Under the new job specific work system, PHNs working in a PHC are involved in one of five major areas of services: (1) health services for adults and the aged; (2) services for mothers and children; (3) services related to infectious diseases; (4) services related to intractable diseases; and (5) mental health services. ${ }^{18}$ We focused on PHNs engaged in mental health services (community psychiatric nurses) when conducting this survey. Community psychiatric nurses are said to experience greater physical and mental fatigue due to problems with working conditions (inadequate support systems) and unsatisfactory regional emergency mental health care systems. However, no studies have systematically examined evidence supporting this view. The aim of the present study was therefore to investigate whether prevalence of burnout is higher among community psychiatric nurses working under the recently introduced job specific work system than among PHNs engaged in other public health services. In addition, factors contributing to burnout were identified, and three major categories related to the work environment (support systems, PHN relationship with physicians, and emergency service systems at PHCs) were examined.

\section{METHODS}

In Japan, 448 PHCs are operated by prefectures, which are similar to counties in the UK. ${ }^{19}$ Of these, 356 have adopted the job specific work system, although the number of community psychiatric nurses was unknown at 27 of the 356 PHCs. Community psychiatric nurses working at 329 PHCs were therefore requested to participate in this survey.

A total of 133 PHCs had only one PHN engaged in public mental health services. For these institutions, that PHC

Abbreviations: PHC, public health centre; PHN, public health nurse; RR, relative risk 
Main messages

- Prevalence of burnout was significantly higher for community psychiatric nurses (prevalence $59.2 \%$ ) than for PHNs engaged in other public health services in this nationwide survey.

- Excessive work demands, particularly for emergency overtime work, and low job control for community psychiatric nurses are work environment factors that appear to contribute to burnout.

- The work characteristics of community psychiatric nurses may be categorised as displaying "high job strain $^{\prime \prime}$.

selected to participate in the present study. The remaining 196 PHCs had two or more PHNs engaged in public mental health services. Under these circumstances, two PHNs were randomly selected as participants. A total of 525 PHNs primarily engaged in public mental health services were therefore selected, forming the psychiatric group. The control group comprised 525 PHNs (one or two nurses selected at random from each of the 327 stations) from the same PHCs and primarily engaged in adult/aged services $(n=132)$, mother/child services $(n=132)$, infectious disease services $(n=131)$, or intractable disease services $(n=130)$. This sample size was sufficient to detect an increased prevalence of burnout in the psychiatric group of $\geqslant 10 \%$, assuming burnout prevalence in the control group of about $50 \%$ as seen in the preliminary survey, with $80 \%$ power at the $5 \%$ level of significance (two tailed test). The required sample size was 408 in each group, for a total of 816. On 5 November 2002, a questionnaire was mailed to all 1050 potential subjects. To avoid any potential disadvantage to respondents associated with responses, the questionnaire was anonymous in design and each respondent sealed and mailed the return envelope by themselves. After the initial deadline for responses had passed, all nurses to whom questionnaires had been sent were mailed a request for participation in the survey, to increase response rate. The questionnaire included a column for obtaining from each respondent informed consent for use of the extracted data in this study.

Instruments for evaluating burnout have been developed by Pines and colleagues, ${ }^{20}$ Maslach and Jackson, ${ }^{21}$ and Jones. ${ }^{22}$ Each of these instruments displays unique characteristics, and selection depends on the specific survey objectives or preferences of the investigator. The Burnout Scale developed by Pines et al has been translated into Japanese and has been used to study burnout among Japanese nurses and PHNs. ${ }^{23}$ The present study utilised Pines' Burnout Scale to measure burnout. The scale is a self diagnosis instrument that includes 21 questions evaluating three factors of burnout: (1) physical exhaustion; (2) emotional exhaustion; and (3) mental exhaustion. Of the 21 items, 17 are negative and four are positive..$^{20}$ Responses to all items utilise a seven point scale. Composite burnout score represents the mean response for all items, with scores for positive items reversed. This scale was previously validated based on a sample of more than 5000 individuals, comprising Americans, Canadians, Japanese, Australians, and Israelis. Construct validity was established using discriminant validity methods, which utilise correlational-type analysis of the target test, with several other relevant measures. The Burnout Scale has also shown high test-retest reliability and internal consistency. ${ }^{25}$

Respondents were classified by burnout score into three groups: group A (score $\leqslant 2.9$; mentally stable, healthy, no

\section{Policy implications}

- To implement the de-institutionalisation that the national government has devised, a system must be established that can both accept discharged patients, and also cope with the emergency care needs of discharged patients.

- Community psychiatric nurses will play a central role in any such system. Countermeasures to improve work environments and prevent burnout among nurses should therefore be implemented.

burnout); group B $(3 \leqslant$ score $\leqslant 3.9$; positive signs, risk of burnout); and group $\mathrm{C}$ (score $\geqslant 4$; burnout present, action required). ${ }^{20}{ }^{23}$ Groups $\mathrm{B}$ and $\mathrm{C}$ were considered to represent a state of "burnout" for the purposes of this study. A separate questionnaire was also prepared to investigate factors providing support for PHNs working in PHCs and the adequacy of emergency mental health service systems. This questionnaire included items pertaining to individual characteristics (age of nurses, population of region covered by each PHC, length of nursing career, etc) and the work environment (actual data on work, work systems, support systems, etc). Prior to the main survey, a preliminary survey of 104 PHNs at 52 PHCs was conducted. Results of the preliminary survey were utilised to improve the validity and reliability of this separate questionnaire.

Relative risk (RR) of burnout for the psychiatric group compared to the control group was determined with $95 \%$ confidence intervals (CI). Gross differences in burnout prevalence between psychiatric and control groups were compared using the Mantel-Haenszel method to adjust for possible confounding effects. Stratified comparisons were performed to adjust for characteristics that differed significantly $(p \leqslant 0.10)$ between psychiatric and control groups. Adjusted RRs, associated 95\% CIs, and p values were calculated using the Mantel-Haenszel test. The Mantel extension test for trends was used to evaluate correlations between burnout and working conditions. These analyses were performed for both groups. Values of $p \leqslant 0.05$ were considered statistically significant. All statistical analyses were based on two tailed probabilities. SPSS for Windows software (version 10.0.5J, SPSS Japan, Tokyo, Japan) was used for statistical analyses.

\section{RESULTS}

Of the 1050 questionnaires sent out, 858 were returned. Responses were received from 423 community psychiatric nurses and 435 nurses engaged in other services (adult/aged services, $\mathrm{n}=112$; mother/child services, $\mathrm{n}=102$; infectious disease services, $\mathrm{n}=109$; intractable disease services, $\mathrm{n}=112$ ). Overall response rate was $81.7 \%$. Of the 858 responses, 625 were collected by the original deadline (primary responses), and 233 were collected after the reminder letter was sent (secondary responses). No significant differences were observed between primary and secondary responses in terms of response tendencies for any questions in the questionnaire. Some respondents answered that they were involved in two or more of the five service categories mentioned above, rather than specialising in one particular service category. These respondents were excluded from analysis. As a result, 785 respondents were included in the final analysis, including 396 community psychiatric nurses and 389 PHNs not engaged in mental health services. The estimate of internal consistency (Cronbach's $\alpha$ ) for the Burnout Scale was 0.94 in the 785 respondents. 
Table 1 Characteristics of PHNs

\begin{tabular}{|c|c|c|c|}
\hline \multirow[b]{2}{*}{ Characteristics } & \multicolumn{2}{|l|}{ Service area } & \multirow[b]{2}{*}{$\mathbf{p}^{*}$} \\
\hline & $\begin{array}{l}\text { Psychiatric health } \\
\text { care, } n=396\end{array}$ & Others, $n=389$ & \\
\hline \multicolumn{4}{|l|}{ Age } \\
\hline$\leqslant 30$ & $35(9)$ & 49 (13) & \\
\hline $31-35$ & 68 (17) & $69(18)$ & \\
\hline $36-40$ & 66 (17) & $81(21)$ & \\
\hline $41-45$ & $106(27)$ & $80(21)$ & \\
\hline $46-50$ & 57 (14) & 53 (14) & \\
\hline$\geqslant 51$ & $64(16)$ & 57 (15) & 0.064 \\
\hline \multicolumn{4}{|l|}{$\begin{array}{l}\text { Population covered by } \\
\text { health centre }(\times 1000)\end{array}$} \\
\hline$<100$ & $124(32)$ & $126(33)$ & \\
\hline $100-150$ & $90(23)$ & $89(23)$ & \\
\hline $150-200$ & $53(14)$ & $56(15)$ & \\
\hline $200-250$ & $38(10)$ & $31(8)$ & \\
\hline $250-300$ & $29(7)$ & $26(7)$ & \\
\hline$>300$ & $58(15)$ & $56(15)$ & 0.968 \\
\hline $\begin{array}{l}\text { Time taken to workshop } \\
\text { (min) }\end{array}$ & $40[20,60]$ & $45[20,60]$ & 0.339 \\
\hline $\begin{array}{l}\text { Career as PHN (y) } \\
\text { Number of years in } \\
\text { current service }\end{array}$ & $19[12,24]$ & $17[11,23]$ & 0.125 \\
\hline$<1$ & $144(36)$ & $181(47)$ & \\
\hline 1 & $57(14)$ & $45(12)$ & \\
\hline $2+$ & $195(49)$ & $163(42)$ & 0.009 \\
\hline
\end{tabular}

Table 1 compares characteristics between psychiatric and control groups. Psychiatric and control groups displayed significant differences in number of years in current service $(\mathrm{p}=0.009)$.

Table 2 shows overall prevalence of burnout for the two groups. Relative risk of burnout was significantly increased for the psychiatric group compared with the control group. Two factors that differed significantly $(p \leqslant 0.10)$ between psychiatric and control groups, age strata and number of years in current service, were examined to adjust for possible confounding effects. Relative risks for overall, age strata, and number of years in current service were significantly increased.

Table 3 shows the association between prevalence of burnout in each group and answers to questions on PHN relationships with physicians, support systems, and emergency service systems at PHCs. Affirmative responses to "Is success or failure of service largely determined by the physician?" were significantly associated with prevalence of burnout in the psychiatric group $(p=0.008)$, but not in the control group $(p=0.868)$. For the question, "How often are emergency overtime services needed per year?", increased annual frequency of emergency overtime services correlated with prevalence of burnout in the psychiatric group $(p=0.014)$, but not in the control group $(p=0.426)$.

\section{DISCUSSION}

The key finding of this study was that prevalence of burnout is significantly higher for community psychiatric nurses than for PHNs engaged in other public health services. Prevalence of burnout reached $59.2 \%$ for community psychiatric nurses. This is higher than the prevalence reported in a previous survey of physicians engaged in emergency paediatric care $(50 \%)$, using the same Pines' Burnout Scale. ${ }^{26}$ Past studies of burnout among medical professionals have focused on hospital based staff, and have revealed unresolved problems pertaining to hospital staff. ${ }^{27-29}$ The present study, however, reveals that more than half of PHNs engaged in community health services at PHCs display some level of burnout, irrespective of the type of public health services provided. This study also shows that the situation is more serious for community psychiatric nurses, who represented the primary focus of this study. We believe the results of this study display external validity, since the study was carefully and adequately designed, and involved PHNs across the country. Furthermore, no previous study of PHNs has been conducted on such a large scale.

The distribution of burnout among community psychiatric nurses displayed two slow peaks: one for the 30s age group; the other for the 50s age group. Differences in burnout prevalence between psychiatric and control groups were particularly noticeable for nurses in their 30s. Community psychiatric nurses in this age bracket have often been pursuing a nursing career for at least a decade, and are in the prime of their life as community psychiatric nurses, possessing large amounts of knowledge and experience. For this reason, high expectations and heavy work demands may be heaped on these nurses by both superiors and subordinates. Levels of expectation and work demands may prove excessive, causing extreme mental and physical exhaustion

\begin{tabular}{|c|c|c|c|c|c|c|c|}
\hline & \multicolumn{4}{|l|}{ Service area } & & & \\
\hline & \multicolumn{2}{|c|}{$\begin{array}{l}\text { Psychiatric health care, } \\
n=387\end{array}$} & \multicolumn{2}{|c|}{ Others, $n=377$} & \multicolumn{3}{|c|}{$\begin{array}{l}\text { Comparison between psychiatric } \\
\text { health care and others }\end{array}$} \\
\hline & Burnout, \% & $(95 \% \mathrm{Cl})$ & Burnout, \% & $(95 \% \mathrm{Cl})$ & RR & $(95 \% \mathrm{Cl})$ & $p$ \\
\hline All & 59.2 & (54.3 to 64.1$)$ & 51.5 & (46.4 to 56.5 ) & $1.15^{*}$ & $(1.01 \text { to } 1.31)^{*}$ & $0.032 \dagger$ \\
\hline \multicolumn{8}{|l|}{ Age } \\
\hline$\leqslant 30$ & 58.8 & & 61.2 & & & & \\
\hline $31-35$ & 65.7 & & 50.7 & & & & \\
\hline $36-40$ & 64.1 & & 51.9 & & & & \\
\hline $41-45$ & 53.3 & & 41.0 & & & & \\
\hline $46-50$ & 57.9 & & 54.0 & & & & \\
\hline$\geqslant 51$ & 58.3 & & 55.8 & & $1.17 \ddagger$ & (1.03 to 1.33$) \ddagger$ & $0.022 \S$ \\
\hline \multicolumn{8}{|c|}{$\begin{array}{l}\text { Years in } \\
\text { current service }\end{array}$} \\
\hline$<1$ & 62.3 & & 50.3 & & & & \\
\hline 1 & 64.8 & & 46.5 & & & & \\
\hline $2+$ & 55.4 & & 54.1 & & $1.15 \ddagger$ & $(1.01$ to 1.31$) \ddagger$ & $0.037 \S$ \\
\hline
\end{tabular}

${ }^{*}$ Crude relative risk and $95 \%$ confidence interval. $+\chi^{2}$ test. $\ddagger$ Adjusted relative risks and $95 \%$ confidence intervals using the Mantel-Haenszel method. $\S$ Mantel-Haenszel test. 
Table 3 Prevalence of burnout among PHNs, stratified by service area and working conditions

\begin{tabular}{|c|c|c|c|c|c|c|}
\hline \multirow[b]{3}{*}{ Working conditions } & \multicolumn{6}{|c|}{ Service area } \\
\hline & \multicolumn{3}{|c|}{ Psychiatric health care, $n=387$} & \multicolumn{3}{|c|}{ Others, $n=377$} \\
\hline & Total & Burnout (\%) & $\mathbf{p}^{*}$ & Total & Burnout (\%) & $\mathbf{p}^{*}$ \\
\hline \multicolumn{7}{|l|}{ Support status } \\
\hline \multicolumn{7}{|l|}{ PHNs in service } \\
\hline $3+$ & 171 & 57.9 & & 61 & 52.5 & \\
\hline 2 & 134 & 57.5 & & 115 & 48.7 & \\
\hline 1 & 69 & 63.8 & 0.531 & 172 & 54.7 & 0.619 \\
\hline \multicolumn{7}{|c|}{ Staff members other than PHNs } \\
\hline $2+$ & 107 & 50.5 & & 75 & 48.0 & \\
\hline $0 / 1$ & 176 & 61.9 & 0.064 & 136 & 53.7 & 0.473 \\
\hline \multicolumn{7}{|c|}{ Help by PHNs in other service areas } \\
\hline Sufficient & 85 & 41.2 & & 99 & 41.4 & \\
\hline Moderate & 221 & 63.3 & & 199 & 50.3 & \\
\hline Seldom & 62 & 67.7 & & 67 & 65.7 & \\
\hline Not at all & 15 & 60.0 & 0.004 & 12 & 75.0 & 0.001 \\
\hline \multirow{2}{*}{\multicolumn{7}{|c|}{$\begin{array}{l}\text { Emergency services after usual business hours } \\
\text { Night/holiday duty rotation system }\end{array}$}} \\
\hline & & & & & & \\
\hline Present & 262 & 56.9 & & 178 & 49.4 & \\
\hline Planned/unknown & 19 & 52.6 & & 70 & 52.9 & \\
\hline Absent & 92 & 67.4 & 0.099 & 76 & 55.3 & 0.384 \\
\hline \multicolumn{7}{|c|}{ Frequency of emergency overtime work } \\
\hline None & 39 & 41.0 & & 215 & 48.4 & \\
\hline Less than 5 times/year & 167 & 58.1 & & 107 & 56.1 & \\
\hline More than 6 times/year & 172 & 64.0 & 0.014 & 49 & 51.0 & 0.426 \\
\hline \multicolumn{7}{|c|}{ Service schedule disturbed by emergency services } \\
\hline Never & 10 & 40.0 & & 100 & 44.0 & \\
\hline Rarely & 54 & 48.1 & & 144 & 50.7 & \\
\hline Sometimes & 180 & 56.1 & & 83 & 55.4 & \\
\hline Often & 141 & 68.8 & 0.002 & 38 & 68.4 & 0.011 \\
\hline \multicolumn{7}{|l|}{ Relations to physicians } \\
\hline \multicolumn{7}{|l|}{ Physician needed } \\
\hline Never & 46 & 47.8 & & 284 & 51.8 & \\
\hline Rarely & 86 & 58.1 & & 50 & 52.0 & \\
\hline Sometimes & 109 & 66.1 & & 16 & 56.3 & \\
\hline Often & 135 & 60.7 & 0.169 & 5 & 60.0 & 0.730 \\
\hline \multicolumn{7}{|c|}{ Physician difficult to secure when needed $\dagger$} \\
\hline Never & 18 & 38.9 & & 17 & 35.3 & \\
\hline Rarely & 58 & 62.1 & & 26 & 61.5 & \\
\hline Sometimes & 108 & 58.3 & & 20 & 60.0 & \\
\hline Often & 146 & 67.1 & 0.051 & 7 & 42.9 & 0.450 \\
\hline \multicolumn{7}{|c|}{ Success/failure is dependent on physician } \\
\hline Never & 17 & 35.3 & & 72 & 55.6 & \\
\hline Rarely & 79 & 57.0 & & 66 & 47.0 & \\
\hline Sometimes & 214 & 57.5 & & 151 & 49.0 & \\
\hline Always & 72 & 72.2 & 0.008 & 48 & 60.4 & 0.868 \\
\hline
\end{tabular}

and contributing to burnout. The apex of the second burnout peak was for nurses in their 50s, and may well reflect the influences of reduced physiological functioning and the increasing development of illness that occurs in the 50s.

With regard to nurse relationships with physicians, the most striking difference observed between the psychiatric and control groups was the correlation between prevalence of burnout and percentage of responses, indicating that success or failure of services is perceived as largely dependent on the physicians involved. In the psychiatric group, prevalence of burnout rose significantly with increasing perception of dependence on physicians. No such correlation was noted in the control group. Of the nurses who stated that the success or failure of service was "always" dependent on the physicians involved, $72.2 \%$ experienced burnout. This percentage was higher than that for any other question, meaning that burnout in community psychiatric nurses is closely related to whether the physician needed for a given community psychiatric service satisfies the requests or expectations of nurses. Furthermore, in the psychiatric group, increased frequency of services requiring emergency overtime work elevated the prevalence of burnout. No such correlation was observed in the control group. The implication here is that mental health services differ from other public health services in terms of the nature of cases requiring emergency overtime work, and that mental health services more frequently involve difficult cases that are more likely to cause burnout in PHNs.

The prevalence of burnout recorded by this study may slightly overestimate the real situation, since cases with relatively mild symptoms were also included as cases of burnout according to our criteria. That is, group B (positive signs and risk of burnout) and group C (burnout present and action required) were both deemed representative of burnout. Although the prevalence of burnout needs to be evaluated more carefully, the present study undoubtedly indicates that the prevalence of burnout is higher among PHNs involved in mental health care than among PHNs in charge of other services. Furthermore, considering a British report that one in every two community psychiatric nurses was seriously emotionally drained by their work, ${ }^{30}$ the prevalence of burnout revealed in the present study may not be excessively high. It is plausible to imagine from these studies that as work environments for PHNs in developed countries have undergone rapid changes in recent years, more than a few PHNs have been burdened by great physical and mental stress, possibly causing varying degrees of burnout.

The present study focused only on the work environment, whereas burnout can be caused by factors related to both the workplace and personal and social factors. The significant 
factors identified in the present study cannot completely explain the level of burnout observed in all cases. Relationships between burnout among community psychiatric nurses and personal or social factors must also be examined. Further investigation of the issues surrounding work environment and job stress will add to our understanding of burnout, work environment, and potential preventive measures among community psychiatric nurses. Theories on job stress, particularly the demand-control model described by Karasek, have contributed to the study of job stress by supplying theoretical frameworks with which to explain associations between psychosocial characteristics of the work environment and health outcomes. ${ }^{31} 32$ The demand-control model suggests that a high demand-low control combination at work can contribute to mental and physical pathology. ${ }^{33}{ }^{34}$ In our study, the work environment factor "increased frequency of emergency overtime work" would presumably represent high job demands, and the factors "difficulty securing a physician" and "success/failure is determined by physician" may both represent low job control. The work characteristics of community psychiatric nurses may thus be categorised as displaying "high job strain", and some studies have reported that "high job strain" is associated with mental illness. ${ }^{35}$ In future, associations between work environment, stress levels, and mental illness among community psychiatric nurses should be analysed utilising approaches including not only burnout theories, but also job stress theories, such as the demandcontrol model.

The present study displays several limitations. First, the reliability and validity of the Japanese version of Pines' Burnout Scale, employed in the present study, have yet to be strictly verified. However, a previous study using this version of Pines' Burnout Scale did show the internal validity of the scale. ${ }^{26}$ In the present study, Cronbach's $\alpha$ coefficient was 0.94, indicating a high level of internal consistency for the scale. Second, we performed nine tests for each group in table 3. To adjust for multiple testing we calculated adjusted $\mathrm{p}$ values of those tests that had displayed significance before adjusting using the Holm method. ${ }^{36}$ In analyses of the psychiatric group, the resulting $\mathrm{p}$ values were $0.032,0.084$, 0.018 , and 0.056 for the working conditions "help by PHNs in other service areas", "frequency of emergency overtime work", "service schedule disturbed by emergency services", and "success/failure is dependent on the physician", respectively. The possibility cannot be excluded that multiple testing might have contributed to spurious significant results for "frequency of emergency overtime work" and "success/ failure is dependent on the physician".

In conclusion, our study shows that prevalence of burnout is significantly higher for community psychiatric nurses than for PHNs engaged in other services. Excessive work demands, particularly for emergency overtime work, and low job control for community psychiatric nurses appear to represent work environment factors contributing to burnout. Countermeasures to improve the work environment and thus prevent burnout among nurses need to be implemented.

\section{ACKNOWLEDGEMENTS}

We are grateful to Naoyasu Iwamoto MD, Akiko Takahashi PHN, and Atsuko Motoyama PHN for their constructive comments and data collection. We wish to thank the members of the research project for their contributions. This study was funded by the Japan Public Health Association.

\section{Authors' affiliations}

H Imai, H Nakao, M Tsuchiya, Y Kuroda, T Katoh, Department of Public Health, School of Medicine, Miyazaki Medical College, 5200 Kihara, Kiyotake, Miyazaki Prefecture 889-1692, Japan

\section{REFERENCES}

1 Visser MR, Smets EM, Oort FJ, et al. Stress, satisfaction and burnout among Dutch medical specialists. CMAJ 2003;168:271-5

2 Lee I, Wang HH. Perceived occupational stress and related factors in public health nurses. J Nurs Res 2002;10:253-60.

3 Linzer M, Visser MR, Oort FJ, et al. Society of General Internal Medicine (SGIM) Career Satisfaction Study Group (CSSG). Predicting and preventing physician burnout: results from the United States and the Netherlands. Am J Med 2001;111:170-5.

4 Palsson MB, Hallberg IR, Norberg A, et al. Burnout, empathy and sense of coherence among Swedish district nurses before and after systematic clinical supervision. Scand J Caring Sci 1996;10:19-26.

5 Pines A, Maslach C. Characteristics of staff burnout in mental health settings. Hosp Community Psychiatry 1978;29:233-7.

6 Gundersen L. Physician burnout. Ann Intern Med 2001;135:145-8.

7 Cherniss C. Beyond burnout: helping teachers, nurses, therapists, and lawyers recover from stress and disillusionment. New York: Routledge, 1995.

8 Maslach C, Schaufeli WB, Leiter MP. Job burnout. Annu Rev Psychol 2001;52:397-422.

9 Denton M, Zeytinoglu I, Davies S, et al. Job stress and job dissatisfaction of home care workers in the context of health care restructuring. Int J Health Serv 2002;32:327-57.

10 Evans L. An exploration of district nurses' perception of occupational stress. Br J Nurs 2002;11:576-85.

11 Matsuda S. The health and social system for the aged in Japan. Aging Clin Exp Res 2002;14:265-70.

12 Lai OK. Long-term care policy reform in Japan. J Aging Soc Policy $2001 ; 13(2-3): 5-20$.

13 Watts J. Japan starts on health-spending slowdown. Lancet $2001 ; 358$ : 647.

14 Ikegami N, Campbell JC. Health care reform in Japan: the virtues of muddling through. Health Aff (Millwood) 1999; 18(3):56-75

15 Blair A, Littlewood M. Sources of stress. J Community Nurs 1995;9: 38-40.

16 Traynor $M$. The views and values of community nurses and their managers: research in progress - one person's pain, another person's vision. J Adv Nurs 1994;20(1):101-9

17 Health and Welfare Statistics Association. Community Health Act. Journal of Health and Welfare Statistics 2000;47(9):20-1.

18 Ohno A, Yajima M, Mori Y, et al. The role of public health nurses at public health centers after community health act implementation. Kitakanto Med J 2000;50:127-37.

19 Health and Welfare Statistics Association. Activity of public health stations. Journal of Health and Welfare Statistics 2002;49(9): 18-19.

20 Pines A, Aronson E. Burnout. From tedium to personal growth. New York: The Free Press, 1981

21 Maslach C, Jackson SE. Burnout in health professions: a social psychological analysis. In: Sanders GS, Suls J, eds. Social psychology of health and illness. Hillsdale, NJ: Lawrence Erlbaum Associates, 1982:227-51.

22 Jones WJ. The staff burnout scale for health professionals (SBS-HP). Park Ridge, IL: London House, 1980.

23 Inaoka F, Matsuno K, Miyasato K. A study of burnout in nurses and its etiology. Nursing 1984;36:81-103.

24 Matsuno K. Study of "burn out syndrome" among public health nurses and its causative factors. Japan Journal of Public Health 1983;30:503-10.

25 Pines AM. The burnout measure. Paper presented at the National Conference on Burnout in the Human Service, Philadelphia, November 1981.

26 Fields Al, Cuerdon TT, Brasseux CO, et al. Physician burnout in pediatric critical care medicine. Crit Care Med 1995;23:1425-9.

27 Shanafelt TD, Bradley KA, Wipf JE, et al. Burnout and self-reported patient care in an internal medicine residency program. Ann Intern Med 2002;136:358-67.

28 Whippen DA, Canellos GP. Burnout syndrome in the practice of oncology: results of a random survey of 1,000 oncologists. J Clin Oncol $1991 ; 9: 1916-20$.

29 Aiken LH, Clarke SP, Sloane DM. International Hospital Outcomes Research Consortium. Hospital staffing, organization, and quality of care: crossnational findings. Int J Qual Health Care 2002;14(1):5-13.

30 Fagin L, Brown D, Bartlett $\mathrm{H}$, et al. The Claybury community psychiatric nurse stress study: is it more stressful to work in hospital or the community? J Adv Nurs 1995;22:347-58.

31 Karasek RA. Job demands, job decision latitude and mental strain: implications for job redesign. Adm Sci Q 1979;24:285-307.

32 Karasek RA, Theorell T. Healthy work: stress, productivity and the reconstruction of working life. New York, NY: Basic Books, 1990

33 Karasek RA, Theorell T, Schwartz JE, et al. Job characteristics in relation to the prevalence of myocardial infraction in the US health examination survey (HES) and the health and nutrition examination survey (HANES). Am J Public Health 1988;78:910-18.

34 Karasek RA, Baker D, Marxer F, et al. Job decision latitude, job demands, and cardiovascular disease: a prospective study of Swedish men. Am J Public Health 1981;71:694-705.

35 Mausner-Dorsch H, Eaton WW. Psychosocial work environment and depression: epidemiologic assessment of the demand-control model. Am J Public Health 2000;90:1765-70.

36 Holm S. A simple sequentially rejective multiple test procedure. Scand J Statistics 1979;6:65-70. 